\title{
Harmonic Analysis of Electrospindle System with Wavelet Packet Transform
}

\author{
İ. Kıyak
}

\begin{abstract}
The electrospindle systems have been used in the maritime industry, they have recently become operative in automation systems. Along with the widespread use of harmonic generating machines and semi-conductor-based circuits in power and control systems, known reactive power compensation methods have been replaced by the use of filterbased compensation systems that consider harmonic distortion. This study used a voltage signal generated by an electrospindle generator with high harmonic distortion to obtain the amplitude time variation of the fundamental component by using Discrete Wavelet Packet Transform (DWPT). As a result of the analysis, it was observed that this method gives fast and accurate results that can be also used in real-time applications.
\end{abstract}

Index Terms - Electrospindle, discrete wavelet packet transform(DWPT), harmonic analyses, DC motor.

\section{INTRODUCTION}

$\mathrm{E}$ LECTROSPINDLE POWER and motion production systems are composite machines used to produce rotational motion. The first use of these systems is known as the movement suppliers of analog gyroscopes on ships. Subsequently, they began to be used in computer hard disk drive circuits and CNC machines. Nowadays, they are also used in automation systems [1,2].

Today, electricity is produced and distributed only as alternating current energy. The alternating current the consumers draw from the grid consists of two components, the active current and the reactive current. The active power produced by the alternating current is made useful by the consumer, but the reactive power produced by the reactive current does not turn into useful power. Although reactive power cannot be turned into active power, it cannot be totally abandoned. The magnetic field required for normal operation of all operating devices, such as generators, transformers, coils and motors operating according to the electrodynamics principles, is introduced by the reactive current. The most important loads that require industrial compensation include low-voltage synchronous machines, transformers, coils, overhead lines, synchronous motors, rectifiers, induction furnaces, electric arc furnaces, welding machines, induction welding machines, lamp ballasts, rolling mills, electrical circuitry of rolling mills and asynchronous motors $[3,4]$.

I. KIYAK, is with Department of Electrical and Electronics Engineering, Marmara University, 34722, Istanbul, Turkey, (e-mail: imkiyak@marmara.edu.tr).

Manuscript received July 17, 2018; accepted October 28, 2018. DOI: $10.17694 /$ bajece. 444567
Harmonic filters are basically divided into two categories; active filters and passive filters. Active filters are commercially produced and usually used for power factor correction in high-power applications. Passive filters are preferred in cost-effective applications without high energy [5].

The purpose of harmonic filters is to reduce or eliminate the effects of currents or voltages in one or more frequencies, i.e. the level of harmonics. It is aimed to eliminate the technical and economic inconveniences resulting from harmonics caused by filters. The tasks of harmonic filters are;

$>$ To correct the voltage fluctuation of a load fed from a harmonic generating device,

$>$ To prevent unwanted harmonic components introduced into the $\mathrm{AC}$ system,

$>$ To eliminate radio frequency interference [6].

Harmonics that occur in power systems cause improper operation or no operation of equipment, overheating of transformers and motors, interference on communication lines, improper measurements, reduction of the service lives of electrical devices, increased power losses of receivers and systems [7,8]. Additionally, harmonics cause serious problems resulting from resonance in compensation units that are used in industrial plants for correcting the power factor $[9,10]$.

Wavelet analysis is a very powerful signal processing method, especially in the analysis of non-stationary signals [5].

The increase in the operating temperatures of electrical machinery is the most effective parameter influential in the machine's lifespan. The loading period and switching of the machine, operation in hot environment, harmonics and unbalanced operation are the most important factors that increase the operating temperature of the machine[11,12].

This study used a voltage signal generated by an electrospindle generator with high harmonic distortion to obtain the amplitude time variation of the fundamental component by using Discrete Wavelet Packet Transform (DWPT). As a result of the analysis, it was observed that this method gives fast and accurate results that can be used in real-time applications.

\section{DATA ACQUISITION SYSTEM}

The system for receiving data from DC shunt motorsynchronous generator-based electrospindle motor is schematically shown in Figure 1 [13]. 


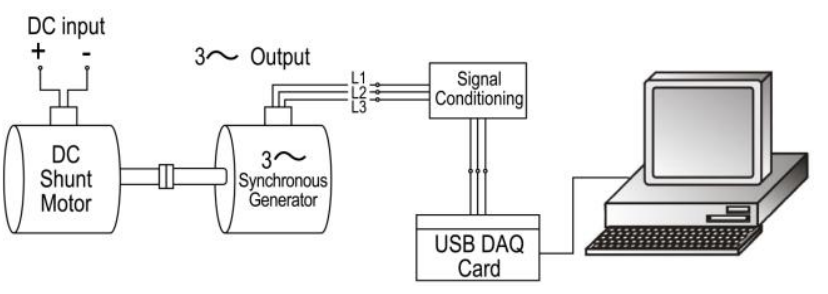

Fig. 1. Schematic Diagram of Data Acquisition System

The real-time data reception link picture of the system components and their connections is shown in Figure 2.

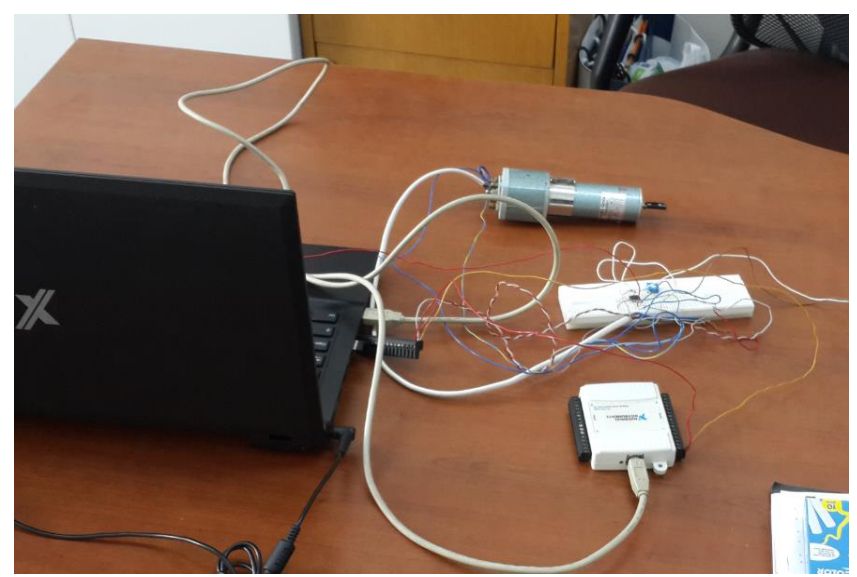

Fig. 2. Data acquisition system used in the study

USB data acquisition card has 14 byte, $48 \mathrm{kS} / \mathrm{s}$ analog digital converter. Rotation speed of DC shunt motor is 6000 $\mathrm{rpm}$, their output voltage is $18 \mathrm{~V}$ and their power is $11 \mathrm{~W}$. Pole number of synchronous generator is four and their frequency is $200 \mathrm{~Hz}$.

Firstly, the voltages generated by the synchronous electrospindle generator were recorded with the data acquisition card at the sampling frequencies of 1600, 4000, 6400 and $12400 \mathrm{~Hz}$. The voltage values of the phase are given in Figure 3-6.

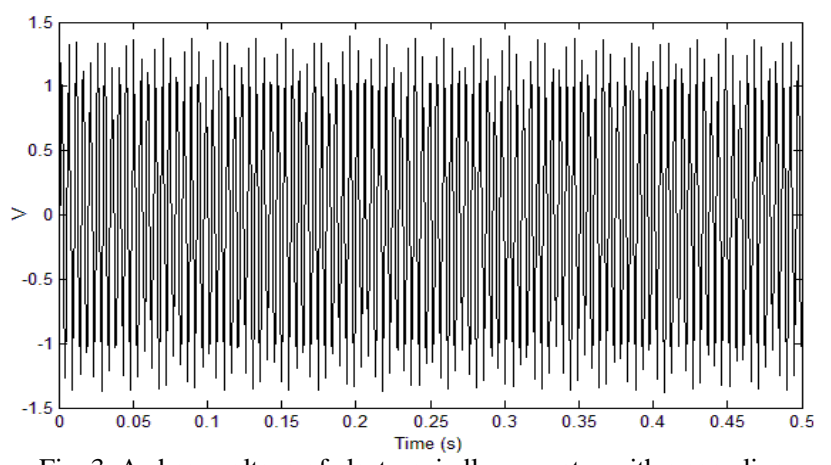

Fig. 3. A phase voltage of electrospindle generator with a sampling frequency of $1600 \mathrm{~Hz}$

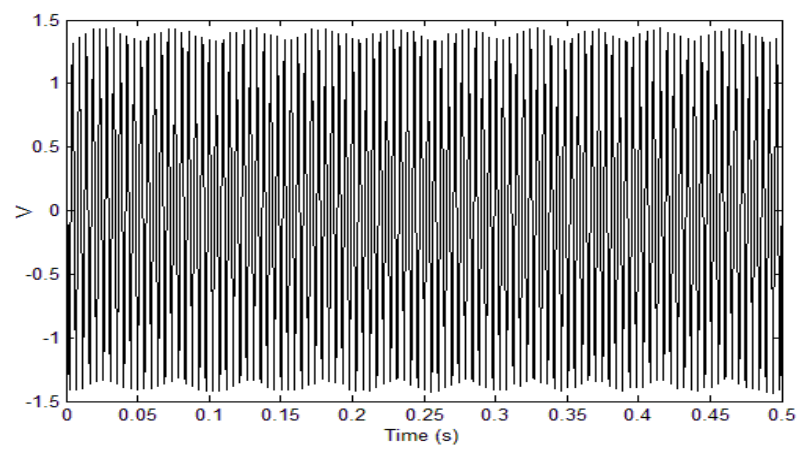

Fig. 4. A phase voltage of electrospindle generator with a sampling frequency of $4000 \mathrm{~Hz}$

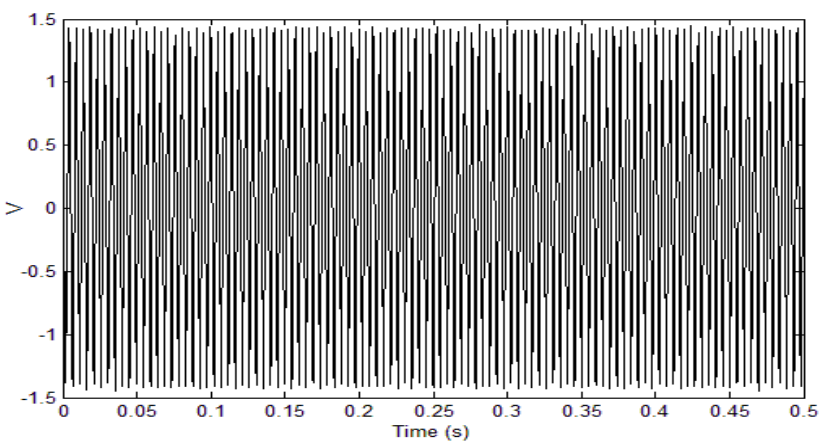

Fig. 5. A phase voltage of electrospindle generator with a sampling frequency of $6400 \mathrm{~Hz}$

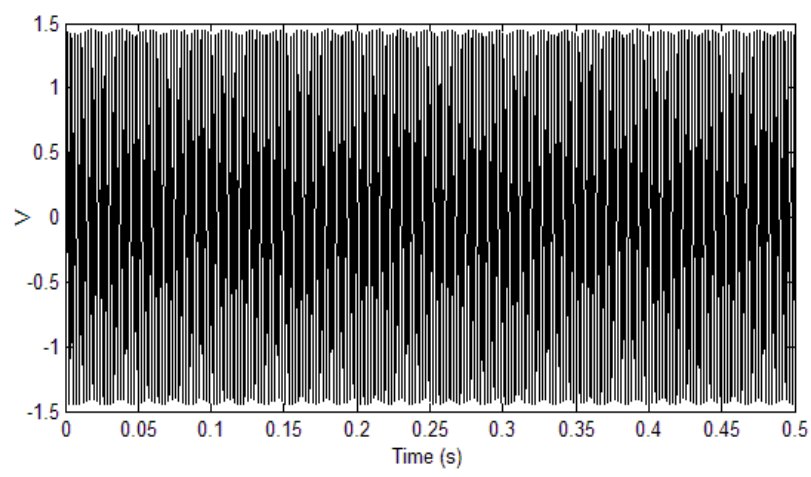

Fig. 6. A phase voltage of electrospindle generator with a sampling frequency of $12400 \mathrm{~Hz}$

\section{DiscRETE WAVELET PACKET TRANSFORM (DWPT)}

After finding the fundamental component of the generated voltages, it is necessary to obtain the amplitude time change of this component. One of the most effective methods to accomplish this is to use Discrete Wavelet Packet Transform (DWPT). With discrete wavelet packet transform, the voltage can be divided into components with fewer coefficients. This is accomplished with low-pass $(g(n))$ and high-pass $(h(n)$ ) filter banks and down-sampling (equations 3-4) [9-15].

$$
\begin{aligned}
& x_{1}^{1}(n)=\sum_{k} X(k) h(2 n-k) \\
& x_{2}^{1}(n)=\sum_{k} X(k) g(2 n-k)
\end{aligned}
$$$$
\text { Here, } X(k) \text { is discrete input signal, } x_{1}^{1}(n) \text { and } x_{2}^{1}(n) \text { are }
$$ 
BALKAN JOURNAL OF ELECTRICAL \& COMPUTER ENGINEERING， Vol. 6, No. 4, October 2018

the filter outputs, coefficients are half of $X(k) . x_{1}^{1}(n)$ and

TABLE I

$x_{2}^{1}(n)$ that are again passed through wavelet filters, and secondary level components are found, while the number of coefficients is again reduced by half [15-16].

$$
\begin{aligned}
& x_{3}^{2}(n)=\sum_{k} x_{1}^{1}(k) h(2 n-k) \\
& x_{4}^{2}(n)=\sum_{k} x_{1}^{1}(k) g(2 n-k) \\
& x_{5}^{2}(n)=\sum_{k} x_{2}^{1}(k) h(2 n-k) \\
& x_{6}^{2}(n)=\sum_{k} x_{2}^{1}(k) g(2 n-k)
\end{aligned}
$$

The same procedure is applied to the second level components to find the third level components, and the number of coefficients is again reduced by half [9-15].

$$
\begin{aligned}
& x_{7}^{3}(n)=\sum_{k} x_{3}^{2}(k) h(2 n-k) \\
& x_{8}^{3}(n)=\sum_{k} x_{3}^{2}(k) g(2 n-k) \\
& x_{9}^{3}(n)=\sum_{k} x_{4}^{2}(k) h(2 n-k) \\
& x_{10}^{3}(n)=\sum_{k} x_{4}^{2}(k) h(2 n-k) \\
& x_{11}^{3}(n)=\sum_{k} x_{5}^{2}(k) g(2 n-k) \\
& x_{12}^{3}(n)=\sum_{k} x_{5}^{2}(k) h(2 n-k) \\
& x_{13}^{3}(n)=\sum_{k} x_{6}^{2}(k) g(2 n-k) \\
& x_{14}^{3}(n)=\sum_{k} x_{6}^{2}(k) g(2 n-k)
\end{aligned}
$$

Thus, in the third level decomposition, eight components are obtained [9-16].

\section{EXPERIMENTAL STUDY}

In order to apply the same wavelet tree to the voltages given in Figures 3-6, the number of data must be the same. For this purpose, the numbers of data of all voltages are converted to 6400 samples [13]. db20 was used as the main wavelet, and the number of coefficients and frequency ranges of the obtained wavelet components are given in Table $1[7,9,18]$.

WAVELET PACKET DECOMPOSITIONS AND FREQUENCY RANGE

\begin{tabular}{ccc}
\hline \hline Decomposition & $\begin{array}{c}\text { Frequency Range } \\
(\mathrm{Hz})\end{array}$ & $\begin{array}{c}\text { Number of Wavelet } \\
\text { Coefficients }\end{array}$ \\
\hline$x_{7}^{3}(n)$ & $2800 \sim 3200$ & 400 \\
$x_{8}^{3}(n)$ & $2400 \sim 2800$ & 400 \\
$x_{9}^{3}(n)$ & $2000 \sim 2400$ & 400 \\
$x_{10}^{3}(n)$ & $1600 \sim 2000$ & 400 \\
$x_{11}^{3}(n)$ & $1200 \sim 1600$ & 400 \\
$x_{12}^{3}(n)$ & $800 \sim 1200$ & 400 \\
$x_{13}^{3}(n)$ & $\left.400 \tau 5^{8}\right)$ & 400 \\
$x_{14}^{3}(n)$ & $0 \sim 400$ & 400
\end{tabular}

As seen in Table 1, the frequency range of $x_{14}^{3}(n)$ was 0$400 \mathrm{~Hz}$, and it contained the fundamental component frequency. By removing the other seven components, the filtered voltages were obtained (Figure 7-11) [7,9,18].

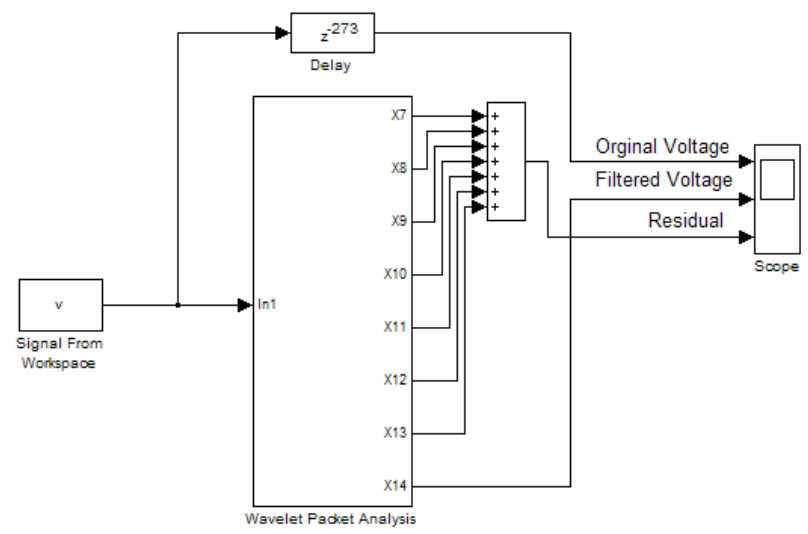

Fig. 7. Simulink Circuit
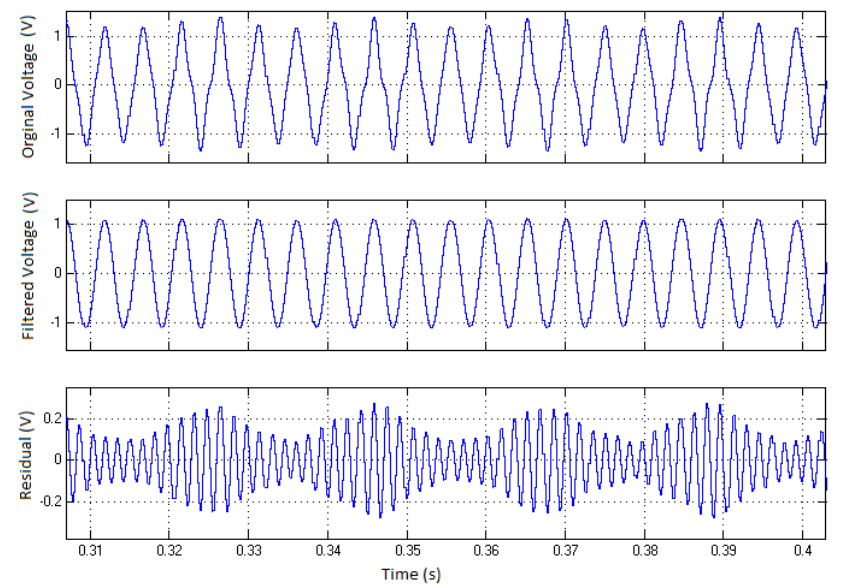

Fig. 8. Generator voltage filtered at $1600 \mathrm{~Hz}$ sampling frequency 

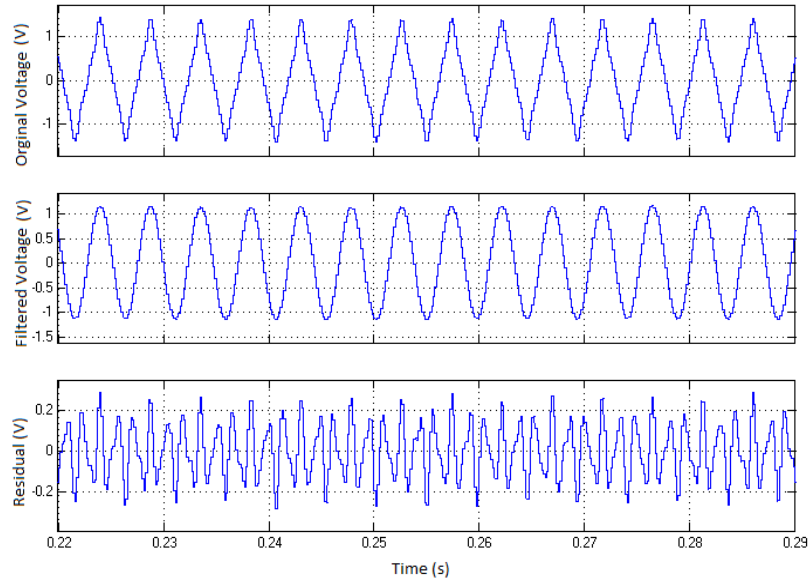

Fig. 9. Generator voltage filtered at $4000 \mathrm{~Hz}$ sampling frequency
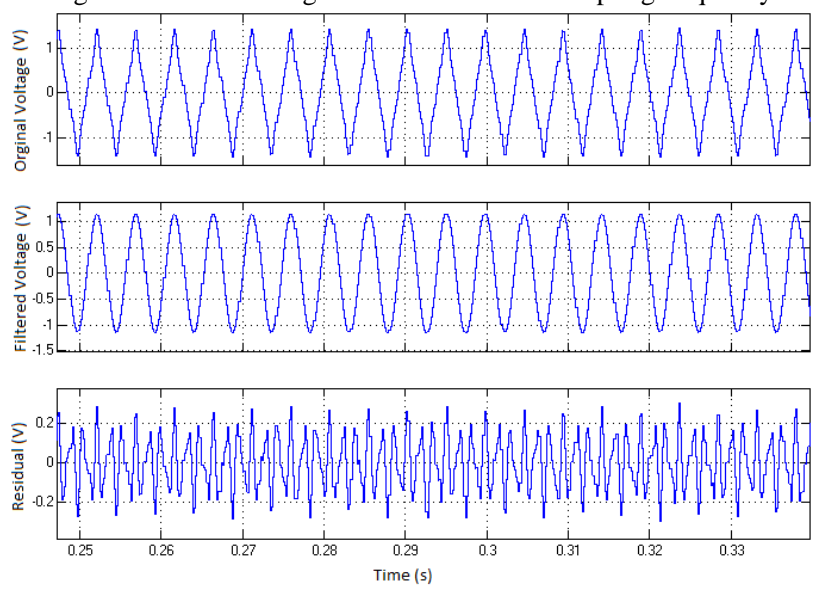

Fig. 10. Generator voltage filtered at $6400 \mathrm{~Hz}$ sampling frequency
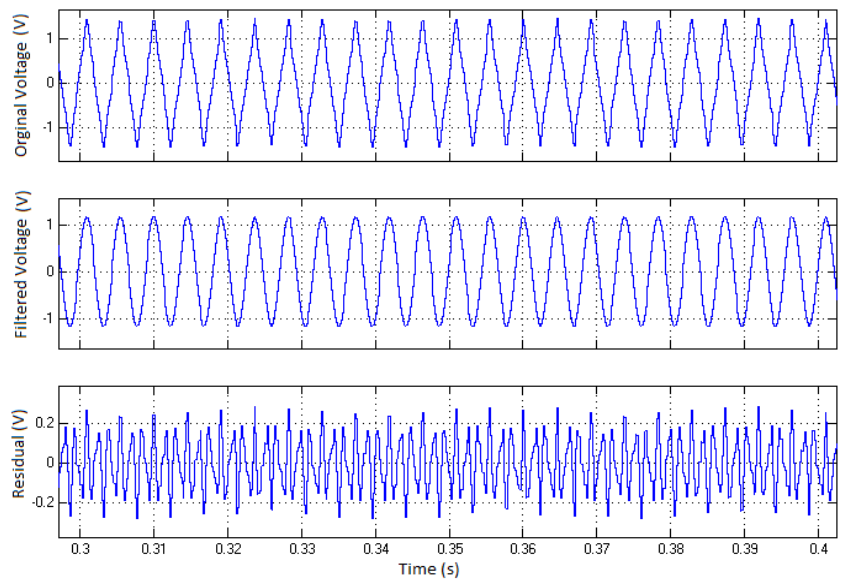

Fig. 11. Generator voltage filtered at $12400 \mathrm{~Hz}$ sampling frequency

When the previous study [13] is examined, it seen that residual of original voltage comprises from $300-800 \mathrm{~Hz}$ harmonic components in Fig.8, the second residual of original voltage comprises from $300-1000 \mathrm{~Hz}$ harmonic components in Fig 9, the third and last residual of original voltage comprise from $300-2700 \mathrm{~Hz}$ harmonic components in Fig 10,11. The filtered voltages always have fundamental frequency around $200 \mathrm{~Hz}$ and its shape is close pure sine waveform.

\section{CONCLUSION}

This study aimed to obtain a more sinusoidal output voltage by removing the harmonics in the output voltage of an electrospindle generator. With DWPT, the generator voltages are divided into components at different frequencies and the fundamental component and harmonic components are obtained.

The filtered voltages given in Figures 8-11 represent the fundamental component, while the residuals represent the sum of the voltages that cause harmonic distortion. The wave shape of the fundamental component was very close to sinusoidal. The Residual values were around $0.2 \mathrm{~V}$. Different residual changes were observed at each sampling frequency. This was because, as the sampling frequency varies, the frequency range covered by the harmonics also varies.

The obtained filtered voltages will increase the operating performance of the gyroscope, but if the gyroscope's nominal operating values are taken into consideration, it may be necessary to increase the output voltage generated by the generator or increase the filtered voltage due to reduction in the amplitude of the filtered voltage.

\section{REFERENCES}

[1] Tamisier V.,Font S., Lacour M., Carrere F., Dumur D., Attenuation of Vibrations due to Unbalance of an Active Magnetic Bearings Milling Electro-Spindle, CIRP Annals- Manufacturing Technology Vol. 50, Issue 1,2001, p. 255-258.

[2] Ziran, L., Wen J., Tao, He., Application of Adaptive Filtering Based on Harmonic Wavelet in the Dynamic Unbalance of Electro-Spindle, Measuring Technology and Mechatronics Automation (ICMTMA), 2010 International Conference on, DOI: 10.1109/ICMTMA.2010.348, 13-14 March 2010.

[3] http://www.mathworks.com/help/matlab/math/fast-fouriertransform-fft.html. Access date 25.03.2014.

[4] Kıyak, İ., Gökmen, G., Kentli, F. "Estimation End Effect of SingleSided Linear Induction Motor by Using Discrete Wavelet Packet Transform and Artificial Neural Network" International Review of Electrical Engineering, Vol.6, n.5, 2011, p.2277-2285.

[5] Robertson C. D., Camps O. I., Mayer J. S., Gish W. B. Wavelets and Electromagnetic Power System Transients. IEEE Transaction on Power Delivery, Vo11, 1996 , No. 2, p. 1050-1058.

[6] The Mathworks, Inc. Signal processing toolbox. User's guide, R2013b, 2013, p. 27-413.

[7] Gokmen G. Wavelet based reference current calculation method for active compansation systems. Electronics and Electrical Engineering, Vol. 108, No. 2, 2011, p. 61-66.

[8] Onat, N., Kıyak, İ., Gökmen, G. "Experimental Wavelet Packet Transient-State Analysis of Electrical Machines Directly Fed by Photovoltaic Cells" International Review of Electrical Engineering, vol. 5 , n.5, 2010, p. 2081-2087.

[9] Janicek F., Mucha M., Ostrozlik M. A new protection relay based on a fault transient analysis using wavelet transform. Journal of Electrical Engineering, Vol. 58, No. 5, 2007, p. 271-278.

[10] http://www.mathworks.com/help/matlab/ref/fft.html. Access date 25.03.2014

[11] Zhu H., Cai M., Wang Q., Chen Y., Controller of High-speed Electro-spindle with AC HMBs Based on Optimal Control Theory, power electronics and motion control conference(IPEMS'2009) IEEE international, V.978, Pp.3557-3563.

[12] Baggini A., Hanzelka Z., Voltage and current harmonics, Handbook of Power Quality, John Wiley \& Sons Press, England, 2008, p. 241249.

[13] Gökmen G., Analog jiroskop sistemlerinde kullanılan elektromekanik döner milli generatörün frekans analizi, DÜMF Mühendislik Dergisi, Vol.9, No. 2, 2018, p. 671-677.

[14] Deng H., Ling H. Fast solution of electromagnetic integral equations using adaptive wavelet packet transform. IEEE Transaction on Antennas and Propagation, Vol. 47, No. 4, 1999, p. 674-682.

[15] The Mathworks, Inc. wavelet toolbox. User's guide, R2014a, 2014, p. $138-224$.

[16] http://www.mathworks.com/help/signal/ug/resampling.html. Access date 25.03.2014.

[17] Saleh S. A., Rahman M. A new transient model for three-phase power transformers using a wavelet filter bank. IEEE Transaction on Power Delivery, Vol. 20, Issue 2, 2005, p. 1409-416. 
BALKAN JOURNAL OF ELECTRICAL \& COMPUTER ENGINEERING， Vol. 6, No. 4, October 2018

[18] Akinci, T.C., Time- Frequency Analysis of the Current Measurement by Hall Effect Sensors for Electric Arc Welding Machine, Mechanika, 5(85), 2010, p. 66-71.

\section{BIOGRAPHY}

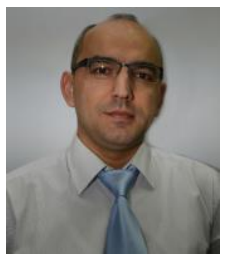

ISMAIL KIYAK, was born in 1977. He received B.S, M.S and $\mathrm{PhD}$ degrees from Marmara University, Istanbul, Turkey. He has been working as a Assoc. Prof. Dr. at Marmara University. His current interests are renewable energy sources, lighting technique, vocational education. 